\title{
ORAL HEALTH STATUS OF CHILDREN UNDERGOING RENAL DIALYSIS IN ALEXANDRIA, EGYPT
}

\author{
Maryam M Quritum ${ }^{1}$ BSC, Maha A Hamza² PhD, Wafaa E Abdelaziz² PhD.
}

\begin{abstract}
INTRODUCTION: Advances in pediatric nephrology have resulted in increased survival rates of children on renal dialysis. Renal failure is characterized by multiple organ involvement, including complications in the soft and hard tissues of the oral cavity. Yet, data regarding the oral health status of Egyptian children on renal dialysis is scarce.

OBJECTIVES: The aim of this study was to assess the oral health conditions (dental caries, oral hygiene, gingival condition, calculus and enamel hypoplasia) of children undergoing renal dialysis, in Alexandria, Egypt compared to matched healthy controls. MATERIALS AND METHODS: This study was conducted on all available (70) end-stage renal disease children undergoing dialysis, aged 6-18 years recruited from Alexandria University Children's Hospital (AUCH) and its outpatient-clinics (nephrology medicine) and from Sporting Student's hospital (Health Insurance). The data were compared with that of a gender and age matched control group. Data were collected using an interview questionnaire and clinical examination. The mean df, DMF, GI, Pl.I and CSI scores were recorded. Enamel hypoplasia recorded according to Alaluusa et al criteria was also assessed.

RESULTS: Dialysis children had significantly higher plaque, gingival, CSI and enamel hypoplasia scores whereas mean DMFT was higher among healthy children. No significant differences were observed between groups regarding dft.

CONCLUSIONS: Children undergoing renal dialysis showed significantly worse oral health conditions than healthy controls except for dental caries status. The results of the study suggest a need for dental advice and supervision, and indicate that dental and medical care should be closely integrated for children with renal failure

KEYWORDS: Renal dialysis, Egyptian children, oral health, Alexandria
\end{abstract}

1. Demonstrator at Dental public health department, Faculty of Dentistry, Alexandria University, Alexandria, Egypt.

2. Professor of Dental public health, Faculty of Dentistry, Alexandria University, Alexandria, Egypt.

Corresponding author:

Email: Maryamquritum@gmail.com

\section{INTRODUCTION}

Chronic renal failure (CRF) is a clinical condition characterized by an irreversible deterioration of renal function that gradually progresses to end-stage renal disease (ESRD) (1). Renal failure is diagnosed when serum creatinine ( $\mathrm{SCr}$ ) value persistently increases above $1.2 \mathrm{mg} / \mathrm{dl}$, while ESRD is the stage when the functional capacity of the kidney remains at only $5 \%-10 \%$ of the original capacity glomerular filtration rate (GFR $<15 \mathrm{~mL}$ $/ \mathrm{min}$ ). Then, the renal replacement therapy (RRT) by dialysis or transplantation is indicated as a life-preserving measure (2-4).

The most common etiological factors responsible for CRF in children are congenital renal diseases such as urological malformations, hereditary nephropathy and glomerular diseases (5). The incidence of CRF continues to rise worldwide (6), being 20 times lower in children than adults (7). It also varies from one country to another, as 6.5 new cases per

year, per million, are detected in Europe (7), compared to 10 to 12 per one million in the United States (8). This makes CRF a significant health care problem.

In Egypt, the prevalence of dialysis patients is presumed to have increased from 10 per million population (pmp), in 1974, to about 165 pmp, in 1995, and reached 225 pmp, in 1999 (9). The highest prevalence was lately found to be 483 pmp, in 2004, as reported by Afifi et al (10) in the ninth annual scientific meeting of the Egyptian Renal Registry, in 2008.

Although chronic kidney disease (CKD) is relatively uncommon in children, yet, it can be a devastating illness with many long-term consequences that will not only influence the child's health, but also have long-term impact on the life of the adult that they will become (11). Such complications include severe growth retardation, as well as delayed physical, sexual , mental and psychological maturation (12). In fact, the mortality rate for children with ESRD receiving dialysis therapy is 30150 times higher than in the general pediatric population and the life expectancy for a child on dialysis is 50 years less than a healthy child $(13,14)$. 
Oral and dental complications can occur as a result of the disease itself or its treatment, in addition to the lack of patients' compliance regarding oral hygiene habits and oral health (15). These symptoms were observed in $90 \%$ of the renal patients (16-18). Among the most common oral and dental complications are uremic stomatitis, reduced salivary flow, xerostomia, ammonia-like smell, poor oral hygiene, increased tendency for plaque and calculus formation as well as gingivitis. Furthermore, dental staining due to iron supplementation (3), enamel hypoplasia and opacities may be also seen due to disturbed calcium and phosphate metabolism $(19,20)$. On the other hand, a low prevalence of dental caries has been observed among CRF patients due to the high plaque $\mathrm{pH}$ which is directly correlated with the salivary urea nitrogen concentration (21). In 2015, Andrade et al (22) concluded that hemodialysis (HD) patients had lower caries experience, higher accumulation of dental plaque and calculus deposition than their healthy counterparts, probably due to the differences found in their salivary biochemical parameters.

Although the new preventive and treatment methods have minimized the complications of chronic renal disease, yet, these therapeutic advances have introduced new problems, including concerns for oral health among children with CRF and ESRD (23).

Since there is inadequate information about this target group, in Alexandria, hence, this study aims to investigate the oral health status of children undergoing renal dialysis. In addition, those children were compared with matched healthy ones, assuming no difference in oral health condition among the two groups.

\section{MATERIAL AND METHODS}

A cross sectional, analytical study was carried out in the governmental hospitals that have units of renal dialysis for children, in Alexandria, namely:-

Alexandria University Children's Hospital -El Shatby hospital- (Nephrology department) as well as its outpatient clinics and Sporting Students' Hospital (Health Insurance). All available patients enrolled in the hospital registry for renal dialysis were surveyed.

Written consent from the child's parent(s) or legal guardian(s) and child assent among the older aged groups were sought together with the approval of the Research Ethics Committee of the Faculty of Dentistry, Alexandria University. All participants were first informed about the study objectives. Formal letters were directed to the University hospital and health insurance authorities in order to obtain their permission and full support to conduct the study.

The total number of patients undergoing renal dialysis included in the study was 70 patients with their ages ranged from 6-18 years. They were examined within a duration of six months from January till June, 2016. On the other hand, an equal number of healthy control, age and gender matched children were recruited from different public schools in Alexandria namely; (Fleming Primary, Abdallah El Nadeem Preparatory and Alraml Secondary schools).

\section{- Inclusion Criteria}

1-All available dentate patients from 6 to 18 years.

2-Written consent from the child's parent(s) or legal guardian(s) and child assent among the older aged groups.

\section{- Exclusion Criteria}

1. Children who refused to undergo clinical examination or whose parents refused to give their approval.

2. Patients who had renal transplantation.

Data collection plan was conducted by two methods:

\section{Parental Questionnaire}

The researcher collected the following information through face-to-face interview with child's parent or guardian as well as his medical records. The questionnaire consisted of three sections; Sociodemographic Data, Medical history and Oral health habits and related behaviors (previous dental visits, oral hygiene habits and snacking habits).

\section{Intraoral examination}

Intraoral examination was performed under good illumination using dental mirror and explorer if needed. Intra-examiner reliability was also assessed, resulted in $91.5 \%$ which indicated perfect agreement.

The dental examination included the following:

a) Caries experience; was assessed following the World Health Organization (WHO) criteria (24), by using DMFT index for permanent dentition and the dft index for primary and mixed dentition

b) Oral hygiene condition: was assessed using Silness and Loe plaque index (PLI) (25).

c) Gingival condition: was assessed using Loe and Silness gingival index (GI) (26).

d) Calculus: was assessed using the 1961 calculus surface index (CSI) developed by Ennever et al (27).

e) Enamel hypoplasia: was assessed using the criteria determined by Alaluusa et al. 1996 (28).

f) Oral signs associated with dry mouth and xerostomia:

Was assessed using the criteria of Greenspan 1996 (29). dry, pale or erythematous oral mucosa, little or no pooled saliva in the floor of the mouth, candidiasis, fissuring or atrophic tongue, cheilosis or fissuring of the lips, angular cheilitis and major Salivary Glands swelling or tenderness.

\section{Statistical analysis}

Data were fed to the computer and analyzed using IBM SPSS software package version 20.0 (30). Qualitative data were described using number and percent. Quantitative data were described using mean, standard deviation, median and range. Difference between the Renal Group and the Healthy Group was analyzed using the chi-square test and Fisher-exact test for qualitative variables and the Mann-Whitney and t- test for quantitative variables. The statistical level of significance was predetermined at $(\mathrm{P}<0.05)$.

\section{RESULTS}

Data were displayed to assess the oral health conditions of children undergoing renal dialysis and their healthy counterparts, in Alexandria. 
Table (1) shows the Socio-demographic data obtained from all the participants in the present research. The age of the study sample ranged from 6-18 years with a mean age of 12.74 ( \pm 3.929$), 12.90( \pm 3.336)$ for children with renal dialysis and healthy children, respectively. The higher percent of the study sample was males accounting for $61.43 \%$ among dialysis children and $55.71 \%$ for healthy one. Socioeconomic status (SES), as represented by education of the parents was mainly belonging to the illiterate category (30\%) and preparatory education (32.86\%) for dialysis group compared to $44.29 \%$ completed university education for healthy controls.

Table (1): Mean and percentage distribution of the study participants by socio-demographic characteristics, Alexandria (2016- 17).

\begin{tabular}{|c|c|c|c|}
\hline Variables & $\begin{array}{c}\text { Dialysis } \\
\text { Children } \\
(\mathrm{N}=70) \\
\end{array}$ & $\begin{array}{c}\text { Healthy } \\
\text { Children } \\
(\mathrm{N}=70) \\
\end{array}$ & $\begin{array}{c}\text { Test of } \\
\text { significance } \\
\text { (p value) }\end{array}$ \\
\hline $\begin{array}{l}\text { Age (years) } \\
- \text { Mean } \pm \text { S.D. } \\
-\quad 95 \% \text { CI for } \\
\text { mean } \\
\end{array}$ & $\begin{array}{l}12.74 \pm 3.929 \\
11.80-13.67\end{array}$ & $\begin{array}{l}12.90 \pm 3.336 \\
12.10-13.69\end{array}$ & \\
\hline \begin{tabular}{ll}
\multicolumn{2}{l}{ Gender } \\
$-\quad$ Male \\
$-\quad$ Female
\end{tabular} & $\begin{array}{l}43(61.43 \%) \\
27(38.57 \%)\end{array}$ & $\begin{array}{l}39(55.71 \%) \\
31(44.29 \%)\end{array}$ & $\begin{array}{l}=0.471 \\
493\end{array}$ \\
\hline \begin{tabular}{l} 
Parents' education \\
- Illiterate* $^{*}$ school \\
- Primary \\
completed \\
- Preparatory school \\
completed \\
- High school \\
completed \\
-College/university \\
\multicolumn{2}{c}{ completed } \\
\end{tabular} & $\begin{array}{c}21(30.00 \%) \\
11(15.71 \%) \\
23(32.86 \%) \\
12(17.14 \%) \\
3(4.29 \%)\end{array}$ & $\begin{array}{c}1(1.43 \%) \\
6(8.57 \%) \\
12(17.14 \%) \\
20(28.57 \%) \\
31(44.29 \%)\end{array}$ & $\begin{array}{c}\mathrm{X}^{2}(\mathrm{df}=5)=48.253 \\
\mathrm{p}<0.0001^{*}\end{array}$ \\
\hline
\end{tabular}

*: Statistically significant $(\mathrm{p}<0.05)$

There was a statistically significant difference in the mean value of filled deciduous teeth (f) and permanent teeth (F) among both groups, where healthy children had higher mean (f) component (0.34 \pm .769$)$ and mean (F) component $(1.07 \pm 1.498)$ than those on dialysis $(0.04 \pm .189)$ and $(0.22 \pm 0.546)$, respectively, as shown in table (2).

Similarly, the total mean DMF accounted for $(1.97 \pm 1.855)$ and $(1.21 \pm 1.483)$ among healthy and dialysis children, respectively.

Children with renal dialysis had significantly higher plaque and gingival indices with mean PL.I and GI of $1.42 \pm 0.52$ and $1.07 \pm 0.31$, respectively, compared to $0.94 \pm 0.48$ and $0.78 \pm 0.38$, respectively, among healthy children. Regarding calculus surface index; dialysis children showed significantly higher mean CSI (8.64 $\pm 4.00)$ than healthy ones $(2.55 \pm 2.24)$.

Enamel hypoplasia accounted for $88.57 \%$ among dialysis children, with nearly half of them (47.14\%) having moderate enamel hypoplasia, compared to only $5.71 \%$ of healthy children. The difference was statistically significant (Table 3).
Table (2): Mean number of the study participants according to caries experience in permanent and mixed dentition in Alexandria (2016-17).

\begin{tabular}{|c|c|c|c|}
\hline Caries experience & $\begin{array}{l}\text { Dialysis } \\
\text { children }\end{array}$ & $\begin{array}{l}\text { Healthy } \\
\text { children }\end{array}$ & $\begin{array}{c}\text { Test of } \\
\text { significance } \\
\text { (p value) }\end{array}$ \\
\hline \begin{tabular}{lc}
\multicolumn{2}{l}{ Decayed teeth (d) } \\
$-\quad$ Mean \pm SD \\
$-\quad$ Median (IQR)
\end{tabular} & $\begin{array}{c}\mathrm{n}=28) \\
1.11 \pm 1.197 \\
1.00(0.00- \\
2.00)\end{array}$ & $\begin{array}{c}(\mathrm{n}=29) \\
1.07 \pm 1.280 \\
1.00(0.00- \\
2.00)\end{array}$ & $\begin{array}{c}\mathrm{Z}_{(\mathrm{MW})}=0.336 \\
\mathrm{p}=0.737\end{array}$ \\
\hline \begin{tabular}{ll}
\multicolumn{2}{l}{ Filled teeth (f) } \\
$-\quad$ & Mean \pm SD \\
- & Median (IQR)
\end{tabular} & $\begin{array}{c}(\mathrm{n}=28) \\
0.04 \pm .189 \\
0.00(0.00- \\
0.00)\end{array}$ & $\begin{array}{c}(\mathrm{n}=29) \\
0.34 \pm .769 \\
0.00(0.00- \\
0.00)\end{array}$ & $\begin{array}{c}\mathrm{Z}_{(\mathrm{MW})}=1.96 \\
\mathrm{p}=0.047^{*}\end{array}$ \\
\hline $\begin{array}{lc}\text { df } & \text { (total score) } \\
- & \text { Mean } \pm \text { SD } \\
- & \text { Median (IQR) } \\
\end{array}$ & $\begin{array}{c}\mathrm{n}=28) \\
1.14 \pm 1.208 \\
1.00(0.00- \\
2.00)\end{array}$ & $\begin{array}{c}\mathrm{n}=29) \\
1.41 \pm 1.376 \\
1.00(0.00- \\
2.00)\end{array}$ & $\begin{array}{c}\mathrm{Z}_{(\mathrm{MW})}=0.698 \\
\mathrm{p}=0.485\end{array}$ \\
\hline \begin{tabular}{l}
\multicolumn{2}{c}{ Decayed teeth (D) } \\
$-\quad$ Median (IQR) \\
$-\quad$ Mean \pm SD
\end{tabular} & $\begin{array}{c}\mathrm{n}=67) \\
0.00(0.00- \\
1.00) \\
0.69 \pm 1.033\end{array}$ & $\begin{array}{c}(\mathrm{n}=69) \\
1.00(0.00- \\
1.00) \\
0.83 \pm 1.028\end{array}$ & $\begin{array}{c}\mathrm{Z}_{(\mathrm{MW})}=0.996 \\
\mathrm{p}=0.319\end{array}$ \\
\hline $\begin{array}{l}\text { Missed teeth (M) } \\
\text { Median (IQR) } \\
\text { Mean } \pm \text { SD }\end{array}$ & $\begin{array}{c}(\mathrm{n}=67) \\
0.00(0.00- \\
0.00) \\
0.30 \pm .969\end{array}$ & $\begin{array}{c}(\mathrm{n}=69) \\
0.00(0.00- \\
0.00) \\
0.07 \pm .261\end{array}$ & $\begin{array}{c}\mathrm{Z}_{(\mathrm{MW})}=1.284 \\
\mathrm{p}=0.199\end{array}$ \\
\hline \begin{tabular}{ll}
\multicolumn{2}{l}{ Filled teeth $(\mathbf{F})$} \\
$-\quad$ & Median $(\mathrm{IQR})$ \\
- & Mean $\pm \mathrm{SD}$ \\
\end{tabular} & $\begin{array}{c}\mathrm{n}=67) \\
0.00(0.00- \\
0.00) \\
0.22 \pm .546\end{array}$ & $\begin{array}{c}(\mathrm{n}=69) \\
0.00(0.00- \\
2.00) \\
1.07 \pm 1.498\end{array}$ & $\begin{array}{c}\mathrm{Z}_{(\mathrm{MW})}=3.947 \\
\mathrm{P}<0.0001^{*}\end{array}$ \\
\hline $\begin{array}{ll}\text { DMF (total score) } \\
-\quad \text { Median (IQR) } \\
-\quad \text { Mean } \pm \text { SD }\end{array}$ & $\begin{array}{c}\mathrm{n}=67) \\
1.00(0.00- \\
2.00) \\
1.21 \pm 1.483 \\
\end{array}$ & $\begin{array}{c}\mathrm{n}=69) \\
1.00(0.00- \\
3.00) \\
1.97 \pm 1.855 \\
\end{array}$ & $\begin{array}{c}\mathrm{Z}_{(\mathrm{MW})}=2.575 \\
\mathrm{p}=0.010^{*}\end{array}$ \\
\hline
\end{tabular}

*: statistically significant $(\mathrm{p}<0.05)$

IQR: Inter-quartile range

MW: Mann-Whitney U test

Table (3): Mean scores of Plaque Index (Pl.I), Gingival Index (GI), Calculus Surface Index (CSI) and percentage of the study participants with enamel hypoplasia, Alexandria (2016-17).

\begin{tabular}{|c|c|c|c|}
\hline Oral conditions & $\begin{array}{c}\text { Dialysis } \\
\text { children } \\
(n=70)\end{array}$ & $\begin{array}{l}\text { Healthy } \\
\text { children } \\
(n=70)\end{array}$ & $\begin{array}{l}\text { Test of } \\
\text { significance } \\
\text { (p value }\end{array}$ \\
\hline \begin{tabular}{ll}
\multicolumn{2}{l}{ Plaque Index (PI.I) } \\
$-\quad$ Mean \pm S.D. \\
$-\quad 95 \%$ CI for mean
\end{tabular} & $\begin{array}{l}1.42 \pm 0.52 \\
1.29-1.54\end{array}$ & $\begin{array}{l}0.94 \pm 0.48 \\
0.82-1.05\end{array}$ & $\begin{array}{c}\mathrm{t}=5.71 \\
\mathrm{p}<0.0001^{*}\end{array}$ \\
\hline $\begin{array}{ll}\text { Gingival Index (GI) } \\
-\quad \text { Mean } \pm \text { S.D. } \\
-\quad 95 \% \text { CI for mean }\end{array}$ & $\begin{array}{l}1.07 \pm 0.31 \\
1.00-1.15\end{array}$ & $\begin{array}{l}0.78 \pm 0.38 \\
0.68-0.87\end{array}$ & $\begin{array}{c}t=5.01 \\
p<0.0001 *\end{array}$ \\
\hline $\begin{array}{l}\text { Calculus Surface } \\
\text { Index (CSI) } \\
-\quad \text { Mean } \pm \text { S.D. } \\
-\quad 95 \% \text { CI for mean }\end{array}$ & $\begin{array}{l}8.64 \pm 4.00 \\
7.68-9.59\end{array}$ & $\begin{array}{l}2.55 \pm 2.24 \\
2.02-3.09\end{array}$ & $\begin{array}{c}\mathrm{t}=11.10 \\
\mathrm{p}<0.0001^{*}\end{array}$ \\
\hline \begin{tabular}{l}
\multicolumn{2}{c}{ Enamel hypoplasia } \\
$-\quad$ No \\
$-\quad$ Yes
\end{tabular} & $\begin{array}{l}8(11.43 \%) \\
62(88.57 \%)\end{array}$ & $\begin{array}{c}66(94.29 \%) \\
4(5.71 \%)\end{array}$ & $\begin{array}{l}X^{2}=96.429 \\
p<0.0001 *\end{array}$ \\
\hline \begin{tabular}{ll}
\multicolumn{2}{l}{ Scoring of enamel } \\
hypoplasia \\
- & None \\
- & Mild \\
- & Moderate \\
- & Sever
\end{tabular} & $\begin{array}{c}8(11.43 \%) \\
20(28.57 \%) \\
33(47.14 \%) \\
9(12.86 \%)\end{array}$ & $\begin{array}{c}66(94.29 \%) \\
3(4.29 \%) \\
1(1.43 \%) \\
0(0.00 \%)\end{array}$ & $\begin{array}{l}X^{2}=97.142 \\
P<0.0001^{*}\end{array}$ \\
\hline
\end{tabular}

*: statistically significant $(\mathrm{p}<0.05)$ 


\section{DISCUSSION}

In the present study, 70 children undergoing renal dialysis, clearly differed from normal children in most measured dental parameters such as; dental caries, gingivitis, calculus formation and enamel hypoplasia.

In CKD, males are generally more commonly affected than females (16), in this study, nearly two thirds of the children on renal dialysis were males which was in agreement with previous research reported in the literature (Table1).

Despite a lack of consensus in the literature on caries prevalence in dialysis children (31), the comparative analysis of this study showed that the DMFT index of children undergoing dialysis was significantly lower than their healthy counterparts (Table 2). The proportion of caries-free children was significantly higher among the dialysis population than among the healthy controls; which was in agreement with the results reported by Abdellatif et al (6), Nunn et al (19), Nakhjavani and Bayramy (23) and Subramaniam et al (32). The significant decrease in caries experience found among the dialysis children could be attributed to the elevated urea levels in the saliva, thus raising the buffering capacity of saliva and $\mathrm{pH}$ above the critical level for enamel demineralization. This would negate the effect of any acid formation resulting from sugar intake and neutralize the acidic $\mathrm{pH}$ in the oral environment $(12,20)$. In addition, high salivary phosphate concentrations found in patients with uremia may facilitate remineralization of incipient carious lesions (33).

In agreement with results reported in the literature $(12,20,22)$, the presence of plaque was significantly higher in dialysis subjects in this work when compared with healthy group (Table 3), which reflects an inadequate oral hygiene and the importance given to general medical care for a chronic disease and prolonged hospitalizations as well as by the effect of the former on the subjects' lifestyle $(12,20)$. Hence, HD patients tend not to prioritize oral health care.

Even though, no significant statistical difference between groups regarding plaque was reported by Abdellatif et al (6) and Martins et al (34), which is probably due to the similar socio-economic levels and oral hygiene neglect by both groups or due to the effect of salivary uraemia and its inhibitory effect on plaque formation in the renal group.

The presence of dental plaque in patients with renal dialysis was associated with gingival inflammation, it was observed in this study that the gingival inflammation was significantly higher in the renal group than in the control group (Table 3 ). This is in agreement with the results reported by other studies $(6,12,22)$, who support the suggestion that although uremic condition as well as the immunosuppressive therapy administered causes an immunosuppressed state, the host is still able to react against a bacterial load.
The presence of gingival inflammation in dialysis patients appears to be controversial in the literature; while some reports indicate reduced gingivitis in these patients (Nunn et al. (19), Ertuğrul et al (33), Martins et al (34)), others indicate no significant difference in gingival inflammation between both groups of children; Bots et al (3), Al-Nowaiser et al (20).

Children undergoing dialysis are more susceptible to increased plaque and calculus formation. The results showed that dialysis children presented a higher dental calculus formation when compared with healthy children (Table 3). These findings are supported by the results of Bots et al (3), Abdellatif et al (6), Davidovich et al (12), Andrade et al (22), Subramaniam et al (32) and Martins et al (34).

The accelerated dental calculus formation could be related to the high calcium and phosphate supplements often used as part of the dietary control to these children which increase the salivary concentration of these ions (35). Another hypothesis is that salivary changes might have contributed to a higher dental calculus deposition in participants with $\mathrm{CKD}$, the high salivary urea levels diffuses into plaque and lead to an elevation of $\mathrm{pH}$ in the dental plaque (3).

Considering that dental plaque deposition precedes dental calculus formation, this reinforces the hypothesis that systemic variables of CKD could be related to dental calculus formation (12). This finding emphasizes the need for further studies examining the influence of complex pathogenic mechanisms arising from CKD on processes in the oral cavity, including examination of saliva composition.

Enamel hypoplasia is a well-known phenomenon in dialysis patients $(6,12,33)$. In the present study, enamel hypoplasia was significantly more prevalent and more severe in dialysis children (88.57\%) than in the control group (Table 3 ).

Nunn et al (19) and Nowaiser et al (20) reported that $83 \%$ and $57 \%$ of their renal patients, respectively, had enamel defects, which was consistent with the finding of this current study. The increased prevalence in this study could be also attributed to several factors such as hypocalcemia, decreased serum levels of 1.25dihydroxycholecalciferol, and increased serum levels of inorganic phosphate and serum parathyroid hormone; causing ameloblast disruption and production of poorly formed enamel.

Subramaniam et al (32), suggested that a diet low in protein along with proteinuria is mainly responsible for defective matrix formation, leading to hypoplasia.

On the other hand, Martins et al (34) and Kho et al. (36), observed that enamel hypoplasia was rare in subjects with CRF. The result of these researchers can possibly be attributed to the age of the subjects in their study and to represent a possible CRF manifestation after crown development of the teeth. 


\section{CONCLUSIONS}

From the results of the present study, the following can be concluded:

Most of the dialysis children had plaque and gingival indices higher than controls, as well as calculus formation. Enamel hypoplasia was recorded with high frequency among the majority of the surveyed dialysis patients who suffered from moderate type. On the other hand, a low prevalence of dental caries was also detected in this group of children despite their poor oral hygiene.

The highly prevalent enamel hypoplasia, poor oral hygiene habits, and the resultant gingival changes in the dialysis group, suggest a need for dental advice and supervision. These children may become at slightly greater risk of developing dental caries later on in life after successful transplant. As a result the oral hygiene habits of these children should be improved and closely monitored through periodic dental check-ups. Therefore, dental and medical care should be closely integrated for dialysis children.

\section{CONFLICT OF INTEREST}

The authors declare that they have no conflicts of interest.

\section{REFERENCES}

1. National Kidney Foundation. Clinical practice guidelines for chronic kidney disease: evaluation, classification, and stratification. Am J Kidney Dis. 2002;39:S1-S266.

2. Koch MJ, Buhrer R, Pioch T, Scharer K. Enamel hypoplasia of primary teeth in chronic renal failure. Pediatr Nephrol. 1999;13:68-72

3. Bots CP, Poorterman JH, Brand HS. The oral healthstatus of dentate patients with chronic renal failure undergoing dialysis therapy. Oral Dis. 2006;12:176-80.

4. Marinho JS, Carmona TI, Loureiro A.Oral health status in patients with moderate-severe and terminal renal failure. Med Oral Patol Oral Cir Bucal. 2007; 12:E305-10.

5. Madani K, Otoukesh H, Rastegar A, Van Why S. Chronic renal failure in Iranian children. Pediatr Nephrol. 2001;16:140-4.

6. Abdellatif AM, Hegazy SA, Youssef JM. The oral health status and salivary parameters of Egyptian children on haemodialysis. Advanced Research J. 2011;2:313-8.

7. Karlijn J, Van Stralen E, Tizard J, Verrina E, Schaefer F, Kitty J et al. Demographics of paediatric renal replacement therapy in Europe: 2007 annual report of the ESPN/ERAEDTA registry. Pediatr Nephrol. 2010;25:1379-82.

8. Trivedi HS, Pang MM. Discrepancy in the epidemiology of non-diabetic chronic renal insufficiency and end - stage renal disease in black and white Americans: The third National Health and Nutrition Examination Survey and United States Renal Data System. Am J Nephrol. 2003;23:448-57.

9. Afifi A, Karim MA. Renal replacement therapy in Egypt: first annual report of the Egyptian Society of
Nephrology, 1996. East Mediterr Health J. 1999;5:1023-9.

10. Afifi AM, Mady GE, Ahmad AA, El-Shar-Kawy ME, Aly AR, Khalil HH. Pattern of renal diseases among elderly Egyptians patients with acute or chronic renal diseases in Ain Shams University and Nasser Institute Hospitals, Cairo, Egypt. J Egypt Soc Parasitol. 2005;35:911-24.

11. Becherucci F, Roperto RM, Materassi M, Romagnani P. Chronic kidney disease in children. Clin Kidney J. 2016;9:583-91.

12. Davidovich E, Schwarz Z, Davidovich M, Eidelman $\mathrm{E}$, Bimstein E. Oral findings and periodontal status in children, adolescents and young adults suffering from renal failure. J Clin Periodontol. 2005;32:1076-82.

13. McDonald SP, Craig JC. Long-term survival of children with end-stage renal disease. N Engl J Med. 2004;350:2654-62.

14. Warady B, Chadha V. Chronic kidney disease in children: the global perspective. Pediatr Nephrol.2007;22:1999-2009.

15. Galili D, Kaufman E, Leviner E, Lowental U. The attitude of chronic hemodialysis patients toward dental treatment. Oral Surg Oral Med Oral Pathol. 1983; 56:602-4

16. Proctor R, Kumar N, Stein A, Moles D, Porter S. Oral and dental aspects of chronic renal failure. J Dent Res. 2005;84:199-208.

17.DeRossi S, Cohen D. Renal disease. In: Greenberg MS, Glick M, Ship JA. Burket's oral medicine. $11^{\text {th }} \mathrm{ed}$. Hamilton: BC Decker; 2008. p363-83.

18. Saini R, Sugandha, Saini S. The importance of oral health in kidney diseases. Saudi J Kidney Dis Transpl. 2010;21:1151-2.

19. Nunn JH, Sharp J, Lambert HJ, Plant ND, Coulthard MG. Oral health in children with renal disease. Pediatr Nephrol. 2000;14:997-1001.

20. Al Nowaiser A, Roberts GJ, Trompeter RS, Wilson M, Lucas VS. Oral health in children with chronic renal failure. Pediatr Nephrol. 2003;18:39-45.

21. Peterson S, Woodhead J, Crall J. Caries resistance in children with chronic renal failure: plaque $\mathrm{pH}$, salivary $\mathrm{pH}$, and salivary composition. Pediatr Res. 1985;19:796-9.

22. Andrade M R , Salazar S L, Reis de Sá L F, Portela M, Pereira A, Soares R M , et al. Role of saliva in the caries experience and calculus formation of young patients undergoing hemodialysis. Clin Oral Invest. 2015;19:1793-80.

23. Nakhjavani YB, Bayramy A. The dental and oral status of children with chronic renal failure. J Indian Soc Pedod Prev Dent. 2007;25:7-9.

24. World Health Organization. Oral health surveys: basic methods, $4^{\text {th }}$ ed. Geneva: Offset publication; 1997.4051 .

25. Silness J, Loe H. Periodontal disease in pregnancy. II. Correlation between oral hygiene and periodontal condition. Acta Odontol Scand. 1964; 22:112-35.

26. Loe H, Sillness J. Periodontal disease in pregnancy. Acta Odontol Scand. 1963;21: 533-9. 
27. Ennever J, Sturzenberger OP, Radike A. W. The calculus surface index method for scoring clinical calculus studies. J. Periodont. 1961; 32:54-7.

28. Alaluusa S, Lukinmaa PL, Koskimies M, Pirinen S, Holttd P, Kallio M, et al. Developmental dental defects associated with long breast feeding. Eur J Oral Sci. 1996;104:493-7.

29. Greenspan D. Xerostomia: Diagnosis and Management .Oncology. 1996;10:7-11.

30. Kirkpatrick LA, Freeney BC. A simple guide to IBM SPSS statistics for version20.0 Student ed. Belmont, Calif, Wadsworth: Cengage Learning; 2013.

31. Andrade MR, Antunes LA, Soares RM, Leão AT, Maia LC, Primo LG. Lower dental caries prevalence associated to chronic kidney disease: a systematic review. Pediatr Nephrol. 2013;29:771-8.

32. Subramaniam P, Gupta M, Mehta A. Oral Health Status in Children with Renal Disorders. J Clin Pediatr Dent. 2012;37: 89-94.

33. Ertugrul F, Elbek-Çubukçu C, Sabah E, Mir S. The oral health status of children undergoing hemodialysis treatment. The Turk J Pediatr. 2003;45:108-13.

34. Martins C, Siqueira WL, Oliveira E, Nicolau J, Primo LG. Dental calculus formation in children and adolescents undergoing hemodialysis. Pediatr Nephrol. 2012; 27:1961-6.

35. Lucas VS, Roberts GJ. Oro-dental health in children with chronic renal failure and after renal transplantation: a clinical review. Pediatr Nephrol. 2005;20:1388-94.

36. Kho HS, Lee SW, Chung SC, Kim YK. Oral manifestations and salivary flow rate, $\mathrm{pH}$, and buffer capacity in patients with end-stage renal disease undergoing hemodialysis. Oral Surg Oral Med Oral Pathol Oral Radiol Endod. 1999;88:316-9.

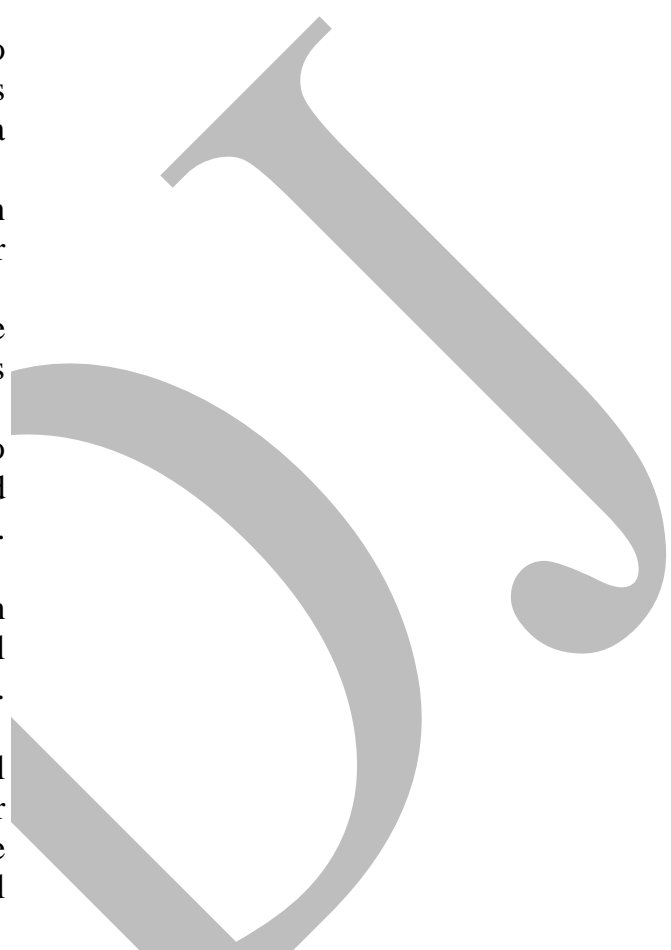

